\title{
Genetic approaches toward understanding the individual variation in cardiac structure, function and responses to exercise training
}

\author{
Minsun Kim and Seung Kyum Kim* \\ Department of Sports Science, Seoul National University of Science and Technology, Seoul 01811, Korea
}

\section{ARTICLE INFO}

Received August 19, 2020

Revised September 18, 2020

Accepted November 2, 2020

\section{*Correspondence \\ Seung Kyum Kim \\ E-mail: skkim7@seoultech.ac.kr}

\section{Key Words}

Exercise

Heart

Multifactorial inheritance

Phenotype

Quantitative trait loci

\begin{abstract}
Cardiovascular disease (CVD) accounts for approximately $30 \%$ of all deaths worldwide and its prevalence is constantly increasing despite advancements in medical treatments. Cardiac remodeling and dysfunction are independent risk factors for CVD. Recent studies have demonstrated that cardiac structure and function are genetically influenced, suggesting that understanding the genetic basis for cardiac structure and function could provide new insights into developing novel therapeutic targets for CVD. Regular exercise has long been considered a robust nontherapeutic method of treating or preventing CVD. However, recent studies also indicate that there is inter-individual variation in response to exercise. Nevertheless, the genetic basis for cardiac structure and function as well as their responses to exercise training have yet to be fully elucidated. Therefore, this review summarizes accumulated evidence supporting the genetic contribution to these traits, including findings from population-based studies and unbiased large genomic-scale studies in humans.
\end{abstract}

\section{INTRODUCTION}

Cardiovascular disease (CVD) is the leading cause of death worldwide [1]. According to the World Health Organization (WHO) fact sheets for CVD reported in 2017, approximately 17.3 million people died from CVDs in 2016, accounting for approximately $31 \%$ of all deaths globally. It has been proposed that, in conjunction with an increase in life expectancy, the medical cost of treating CVDs in the USA will have tripled by 2030 [2]. Accordingly, many medical trials are currently underway with the aim of preventing or treating CVDs, and several therapies, such as $\beta$-adrenergic receptor blockers, aldosterone antagonist, and angiotensin-converting enzyme inhibitors, appear to be effective in preventing morbidity and mortality in patients with CVD [3]. Nevertheless, cases of CVD are evidently increasing and this trend is no longer country-specific $[4,5]$, suggesting the modest effects of current CVD therapies.
Many studies have shown that CVDs are heritable, meaning the genetic components contribute, at least in part, to CVDs. For example, parental CVDs can triple the likelihood of future offspring CVD events [6]. Therefore, efforts have been made in past decades to unveil the genetic basis of CVDs, such as hypertension [7], coronary artery disease [8], atherosclerosis [9], and heart failure [10].

Structural and functional changes in the heart are involved in CVDs. In the setting of disease, the heart, particularly the left ventricle (LV), manifests a structural plasticity called pathological remodeling, which refers to changes in the size, structure, and shape of the heart, ultimately contributing to decreased ejection fraction (EF) and stroke volume (SV) [11]. LV mass, hypertrophy, and wall thickness (WT) have been found to be independent CVD risk factors [12,13]. Accumulating data have provided evidence that the structure and function of the heart are heritable and multifactorial traits, hence, studies have been exerted to

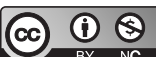

This is an Open Access article distributed under the terms of the Creative Commons Attribution Non-Commercial License, which permits unrestricted non-commercial use, distribution, and reproduction in any medium, provided the original work is properly cited. Copyright @ Korean J Physiol Pharmacol, pISSN 1226-4512, elSSN 2093-3827
Author contributions: Data processing, analysis and writing the original draft: M.K. Conceptualization, funding acquisition, writing the original draft, and editing: S.K.K. 
identify the genetic determinants responsible for cardiac function and structure [14-21]. However, the majority of previous genetic studies (not limited for cardiac traits) were conducted for genotypic effects of a single or only few gene(s), thus were biased and unable to draw comprehensive genome system. Given the polygenic and multifactorial nature of the $\mathrm{CV}$ system, such as cardiac function and structure [22] and population-based biases [23], our understanding of the genetic basis for cardiac physiology remains largely unknown.

Twin and family studies have been used to explore the extent to which genetic factors contribute to the variation of a trait [24]. Assuming that monozygotic (MZ) twins share $100 \%$ of their genetic background and dizygotic (DZ) twins share an average of $50 \%$, direct comparisons between $\mathrm{MZ}$ and $\mathrm{DZ}$ twins can reveal the magnitude of genetic variation in susceptibility to a phenotype [25]. If the phenotype is genetically influenced, a greater correlation is expected for MZ than DZ twins, and if it is $100 \%$ genetically determined (without environmental influence, albeit impossible), the correlation should be doubled in MZ compared to DZ twins, with a heritability $\left(h^{2}\right)$ estimate of $100 \%$ [26]. In this context, twin studies have also been widely used to investigate the genotype $\times$ environment interaction since most traits or diseases are multifactorial. Along the same lines, family studies have long been used to effectively evaluate the genetic architecture of complex traits, such as CVDs [27,28]. Investigation of segregating patterns of a trait from parents to offspring enables the identification of responsible genes [29]. Detailed features of twin and family studies in genetics are reviewed elsewhere [26,28].

There are two general strategies used for discovering genes, more specifically genomic loci, for a certain trait. Linkage studies, which are used to identify the genomic loci responsible for a trait, even with moderate effects, via co-segregating with known genetic markers and estimating the recombination fraction, can only be performed using data collected from biologically related individuals; family members. Meanwhile, association studies assessing correlations between allelic and phenotypic variations can be executed in unrelated individuals from either random or casecontrol samples [28]. Advances in sequencing technologies have provided the foundation for the genome-wide association study (GWAS) [30], which is one of the most commonly used approaches for identifying genetic loci associated with a trait through the investigation of common genetic variation across the entire human genome in a large number of subjects [31]. Although singlenucleotide polymorphisms (SNPs) identified by a GWAS do not necessarily represent their causal effects, GWAS has been found to be a powerful tool, as it can be performed in unrelated subjects and is driven by unbiased hypothesis-free investigations. Through GWAS, candidate and/or putative SNPs associated with various types of CVDs have been identified [32], and some have been curated into the GWAS Catalog database (www.ebi.ac.uk/gwas/). According to the statistics from the GWAS Catalog database, as of July 2020, 125,244 SNP-trait associations have been reported from 4,582 publications. However, in general, the collective effect of loci identified via GWAS explains only a small portion of $h^{2}$; for instance, only $\sim 3.5 \%$ of blood pressure (BP) $h^{2}$ was explained by loci found to be in statistically significant associations [30]. Therefore, further research in the field of CVD genomics is still required, as well as heterogeneous findings from different resources, such as different age, sex, race, and disease state, need to be reconstituted.

Regular exercise is a powerful method of managing CV health [33]. Previous studies have shown that regular exercise not only reduces the incidence and prevalence of CVDs [34], but also decreases all-cause mortality in patients as well as healthy individuals [35]. Strong evidence has demonstrated that regular exercise induces beneficial morphological and functional changes in the heart, including LV dilation and hypertrophy with enhanced contractile function, leading to increased SV or cardiac output (CO or Q) [36-38]. Combined with positive changes in the vascular system due to exercise training [39], exercise-induced morphological and functional alterations in the CV system improve the blood circulation throughout the body, resulting in improved CV health outcomes.

However, recently accumulating data indicate that not all individuals show positive changes following exercise training, and some even had negative outcomes [40-44]. Inter-individual differences in training responses have been highlighted elsewhere $[45,46]$. The previous studies demonstrate a variation in responses to exercise training among individuals, indicating the significant genetic contribution to training responses. This is also supported by previous twin studies showing that the responses of CV-related traits to regular exercise are more correlated in MZ twins compared to DZ twins with estimated $h^{2}$ of $0.22-0.57$, depending on the nature of the response trait [24]. Further, a large consortium study, the HERITAGE Family Study, which examined CV responses to exercise training and investigated genetic influence on training adaptation in $>90$ Caucasian and $>40$ African American families [47], has provided strong evidence that exercise responses are heritable, multifactorial, and complex traits [48-53]. However, there have been few research trials to elucidate the genetic basis underlying responses, particularly in terms of cardiac structure and function, to exercise, suggesting that research in the field of exercise genetics is still in its infancy.

This review aims to summarize accumulated findings from population-based studies and unbiased large genomic scale studies emphasizing the structure and function of the heart. It is presented as a narrative review and detailed information for each single nucleotide polymorphism (allele, location, arbitrary genomic interval, and genes located in the interval) found to be associated with cardiac traits in the previous association/linkage studies is summarized in Tables 1-3. Since exercise genetics is in a state of constant flux with rapidly growing new information, we will also scrutinize the evidence collected from previous studies postulating the genetic contribution to cardiac responses to 


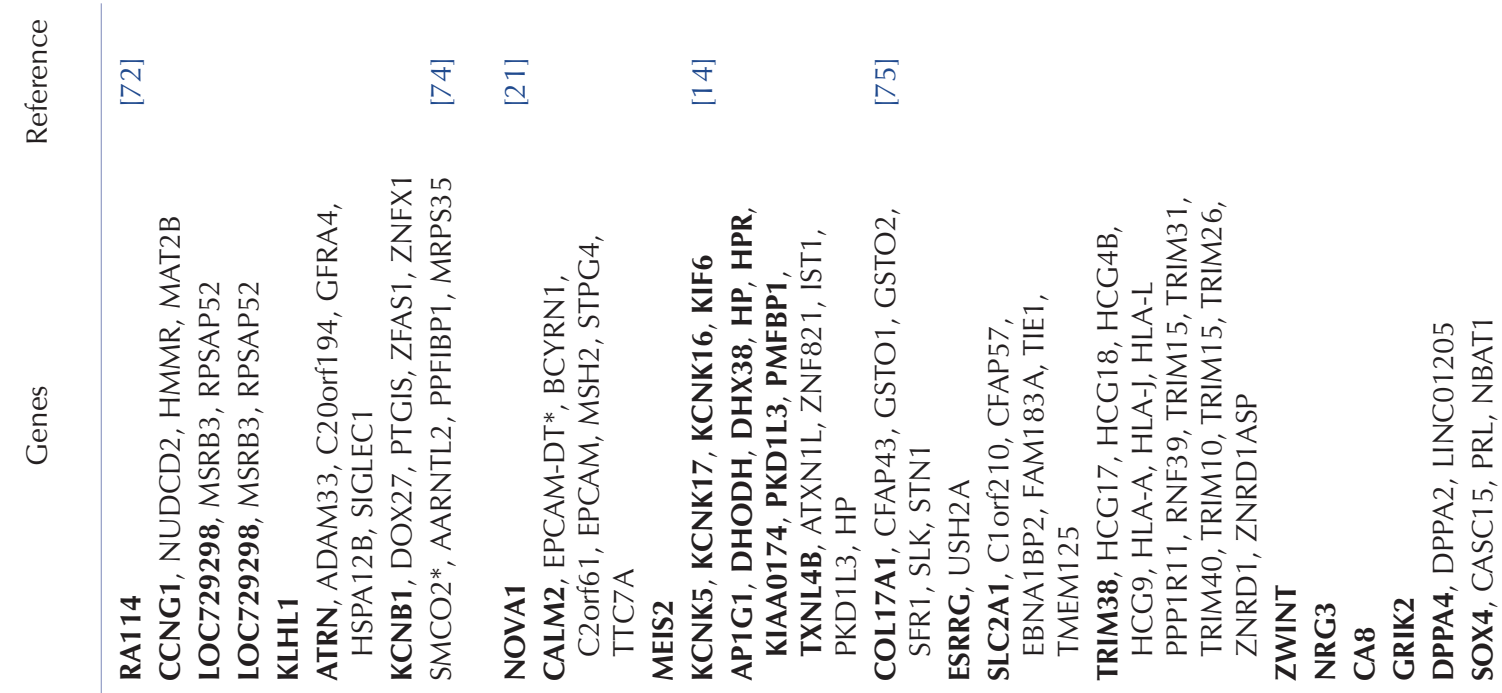

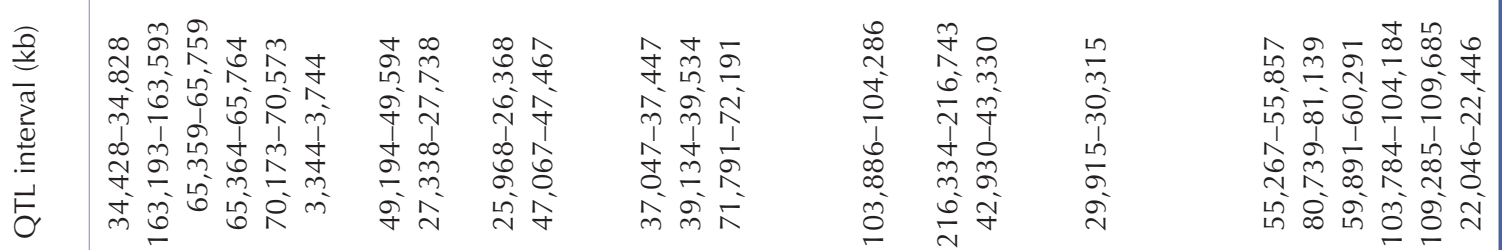

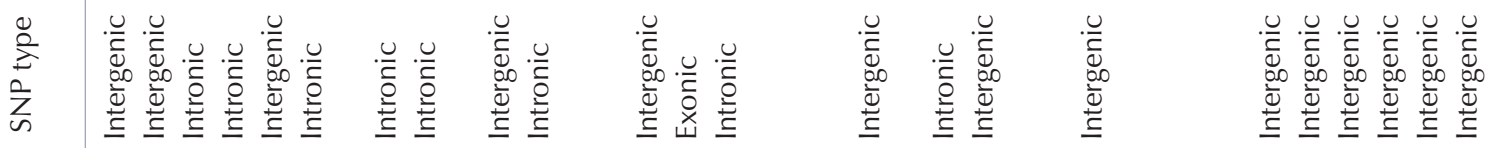

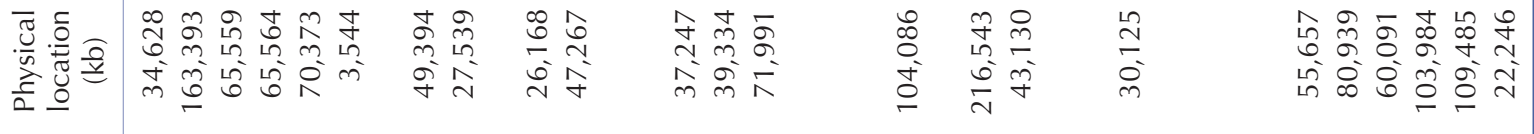

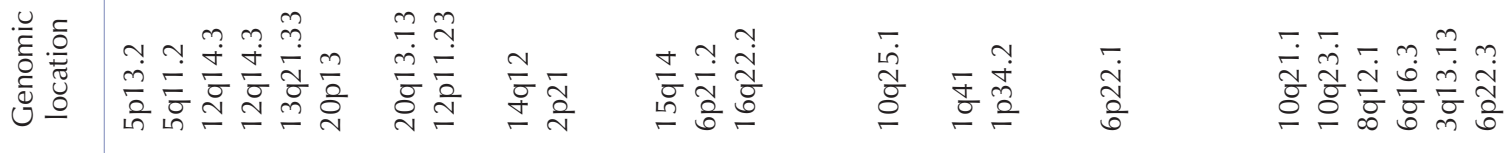

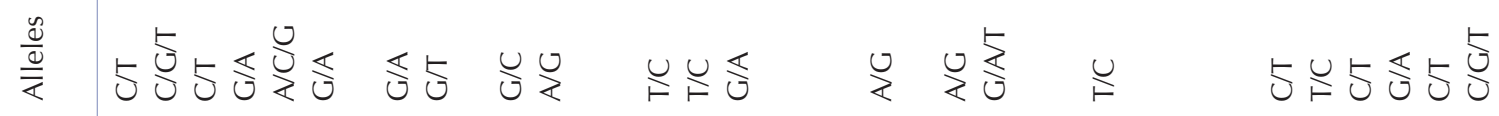

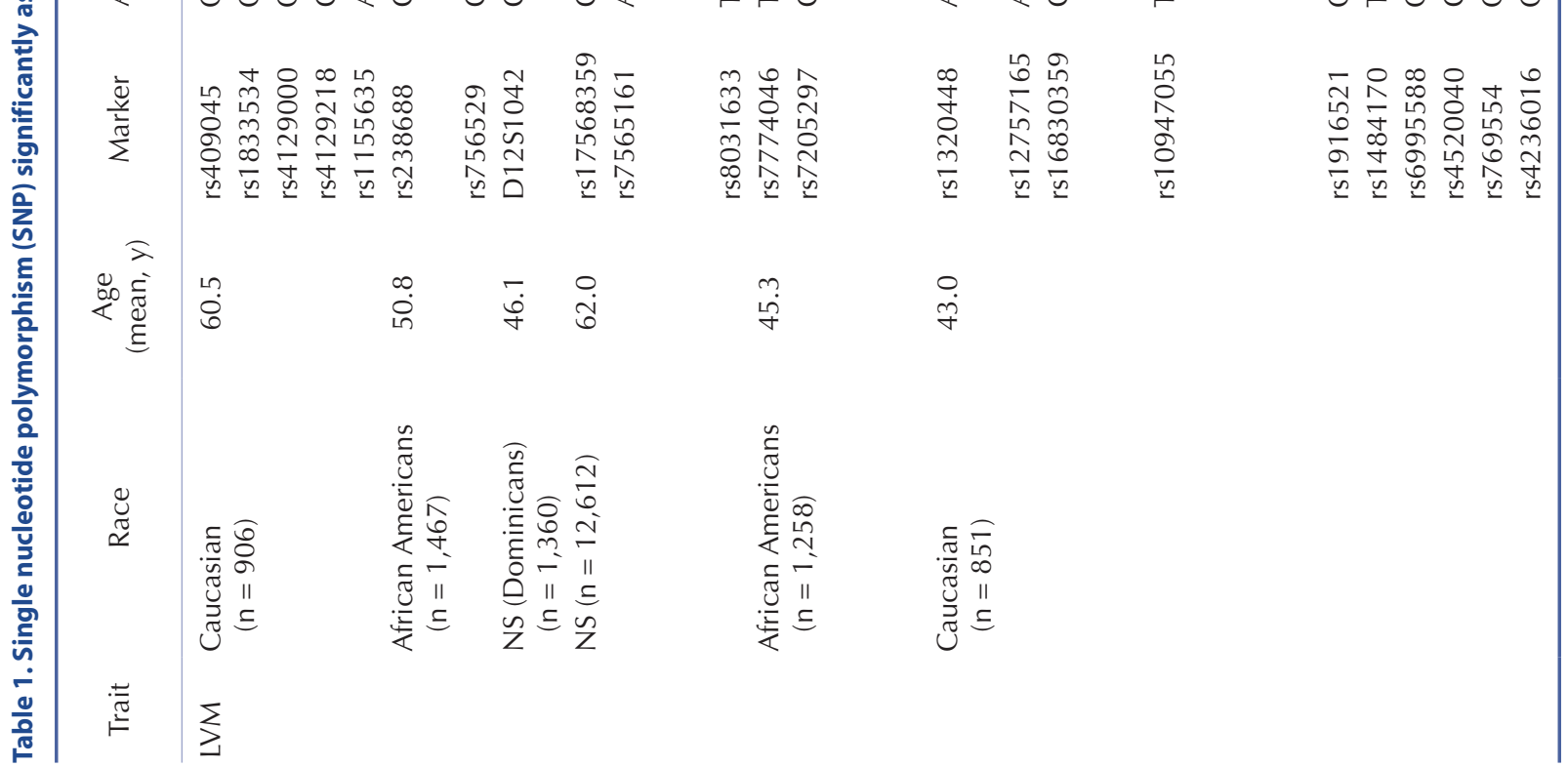




\begin{tabular}{|c|c|c|c|c|c|c|c|c|c|c|c|}
\hline 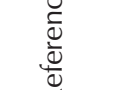 & $\stackrel{\sigma}{\Xi}$ & $\stackrel{\infty}{\stackrel{\infty}{\beth}}$ & & & $\stackrel{\bar{n}}{=}$ & $\overline{\bar{I}}$ & $\stackrel{\sigma}{\Xi}$ & $\stackrel{\infty}{=}$ & \multicolumn{3}{|l|}{$\stackrel{\Xi}{=}$} \\
\hline 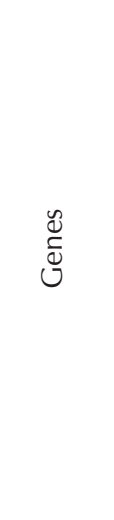 & 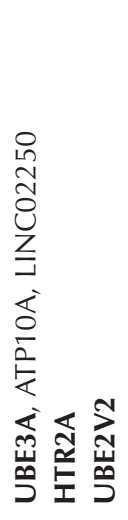 & 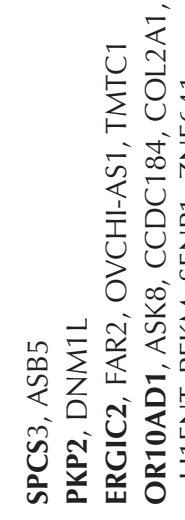 & 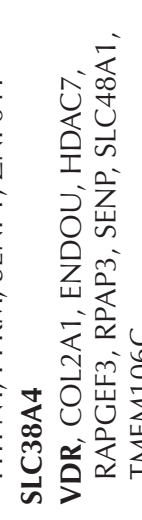 & 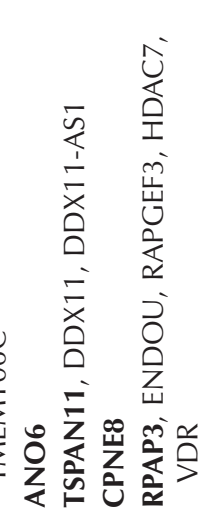 & 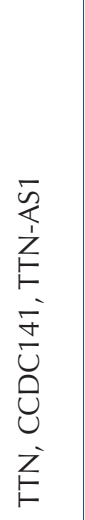 & 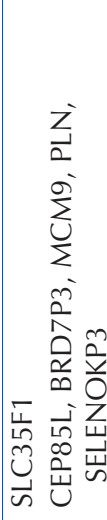 & 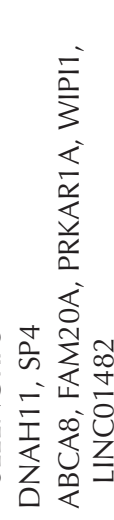 & 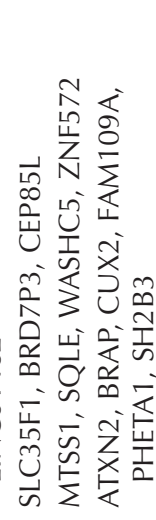 & 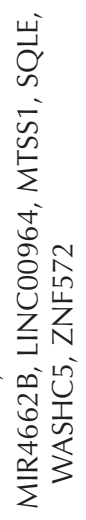 & 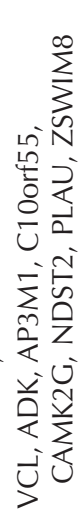 & 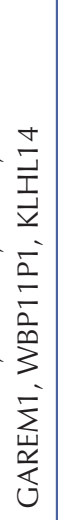 \\
\hline 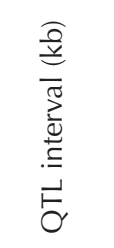 & 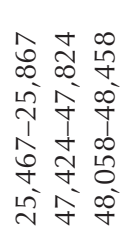 & 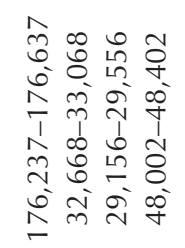 & 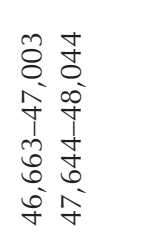 & 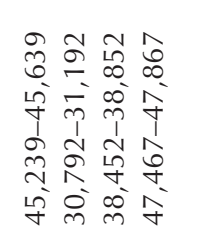 & 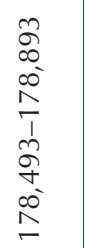 & 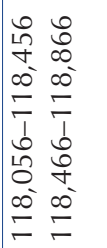 & 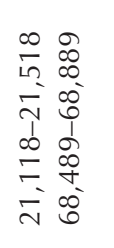 & 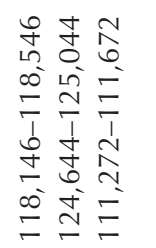 & 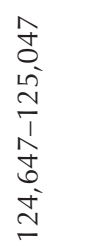 & 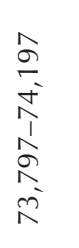 & $\begin{array}{l}\hat{n} \\
\text { o } \\
\text { ì } \\
0 \\
1 \\
\text { ôे } \\
\text { v } \\
\text { ñ }\end{array}$ \\
\hline $\begin{array}{l}\sum_{2}^{0} \\
\sum_{n}^{0} \\
\end{array}$ & 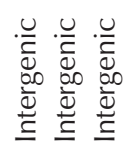 & 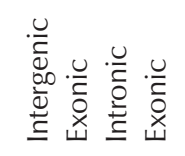 & 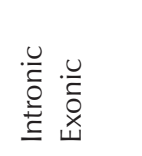 & 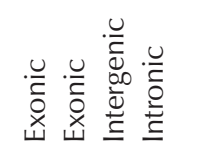 & 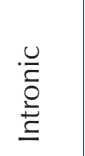 & 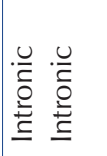 & 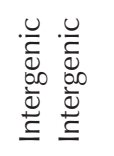 & 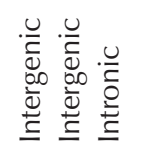 & 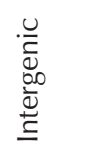 & 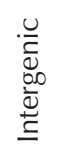 & 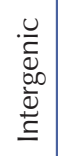 \\
\hline 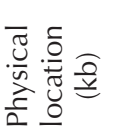 & 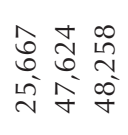 & 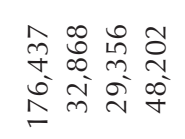 & 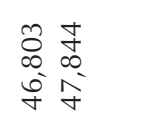 & 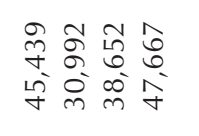 & 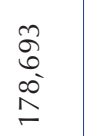 & $\begin{array}{ll}0 & 0 \\
0 & 0 \\
N & 0 \\
0 & 0 \\
0^{0} & \infty 0^{\circ} \\
= & =\end{array}$ & $\begin{array}{ll}\infty & \infty \\
\bar{m} & \infty \\
\bar{\sim} & \infty \\
0^{-}\end{array}$ & 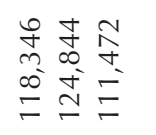 & 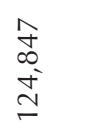 & $\begin{array}{l}\hat{n} \\
\text { ले }\end{array}$ & \begin{tabular}{l}
$\hat{N}$ \\
$o$ \\
\multirow{2}{v}{} \\
$m$
\end{tabular} \\
\hline 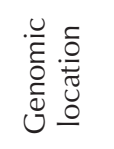 & 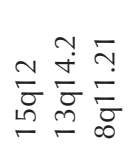 & 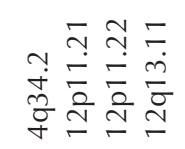 & 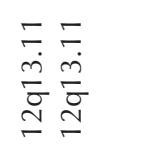 & 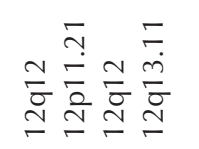 & $\frac{\stackrel{\sim}{~}}{\stackrel{n}{\sim}}$ & 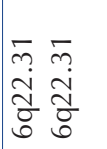 & 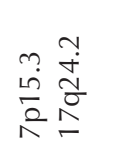 & 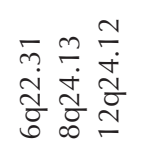 & $\begin{array}{l}m \\
\stackrel{m}{\dot{J}} \\
\stackrel{+}{\square} \\
\infty\end{array}$ & 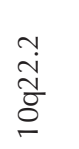 & $\begin{array}{l}\bar{i} \\
\bar{\sigma} \\
\stackrel{\infty}{-}\end{array}$ \\
\hline$\frac{\frac{\tilde{e}}{e}}{\frac{\bar{\varepsilon}}{\alpha}}$ & $\underset{r}{\cup} \stackrel{\cup}{\gtrless}$ & $5 \leqslant \frac{5}{3} \leqslant$ & $\stackrel{0}{<}$ & $\frac{U}{<} \leqslant \frac{U}{2} \frac{U}{<}$ & $\$$ & $\frac{4}{2}$ & $\frac{U}{0} 5$ & 558 & $\frac{\pi}{v}$ & $\stackrel{u}{\&}$ & $\frac{\pi}{v}$ \\
\hline 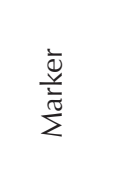 & 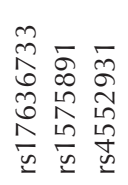 & 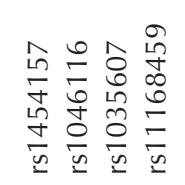 & 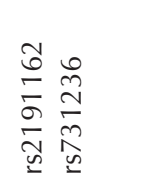 & 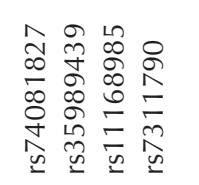 & 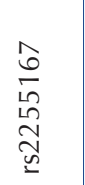 & 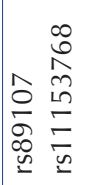 & 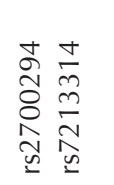 & 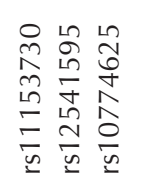 & $\begin{array}{l}\hat{0} \\
\sigma \\
0 \\
0 \\
\infty \\
0 \\
0 \\
0 \\
\omega\end{array}$ & 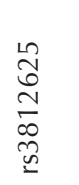 & 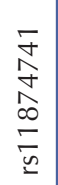 \\
\hline 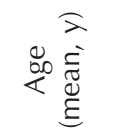 & $\frac{m}{n}$ & $\hat{\mathrm{v}}$ & & & $\stackrel{\llcorner}{i}$ & $\frac{0}{6}$ & $\frac{m}{n}$ & $\hat{\mathrm{j}}$ & $\hat{\jmath}$ & & \\
\hline 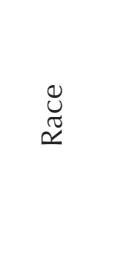 & $<$ & 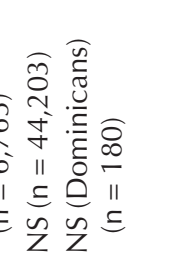 & & & 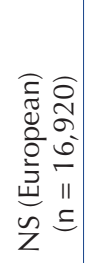 & $\begin{array}{l}0 \\
0 \\
0 \\
0 \\
0 \\
11 \\
11 \\
5 \\
n \\
z\end{array}$ & 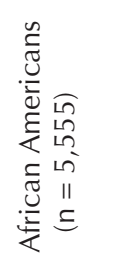 & 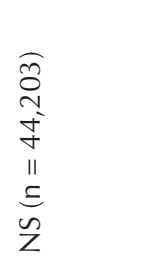 & 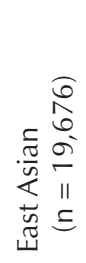 & & \\
\hline & & & & & & & & & & & \\
\hline
\end{tabular}




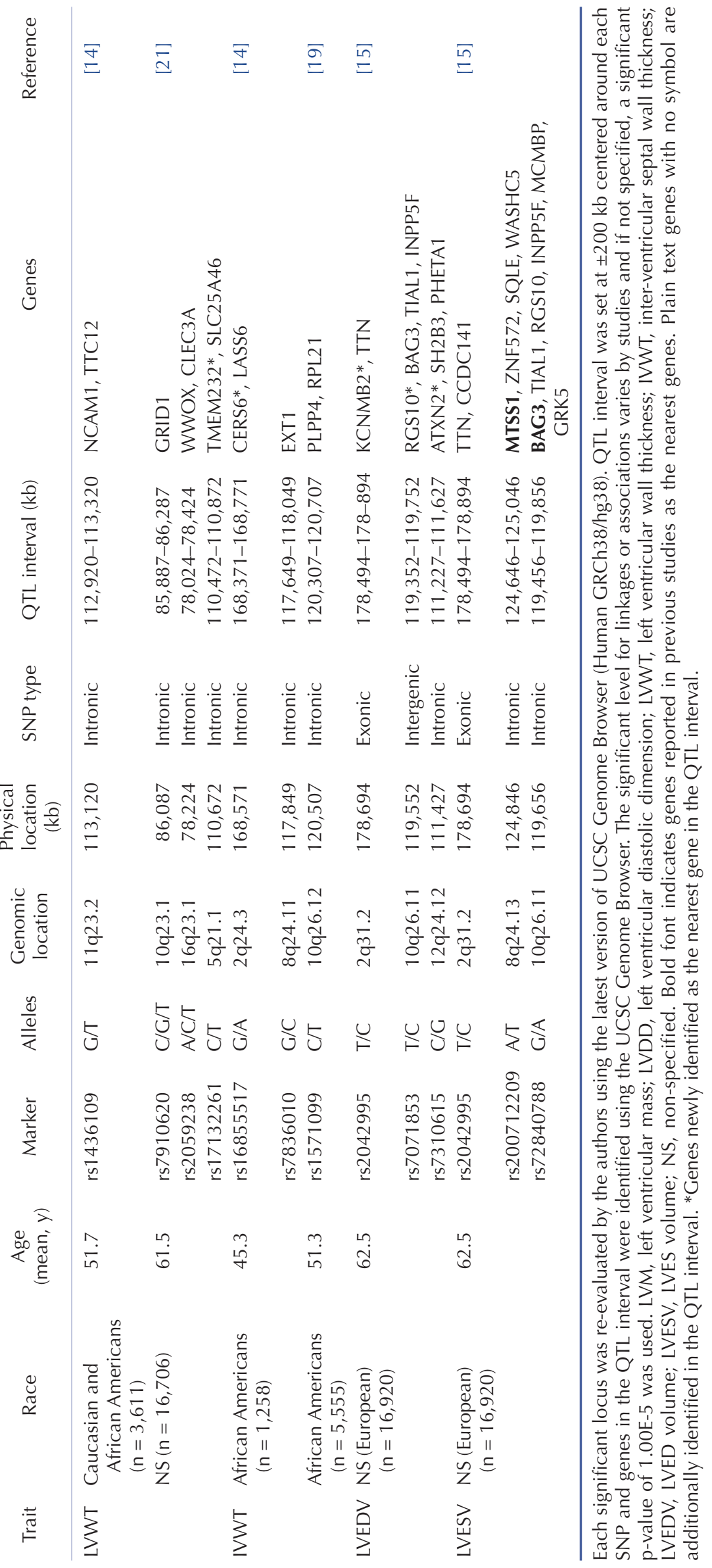




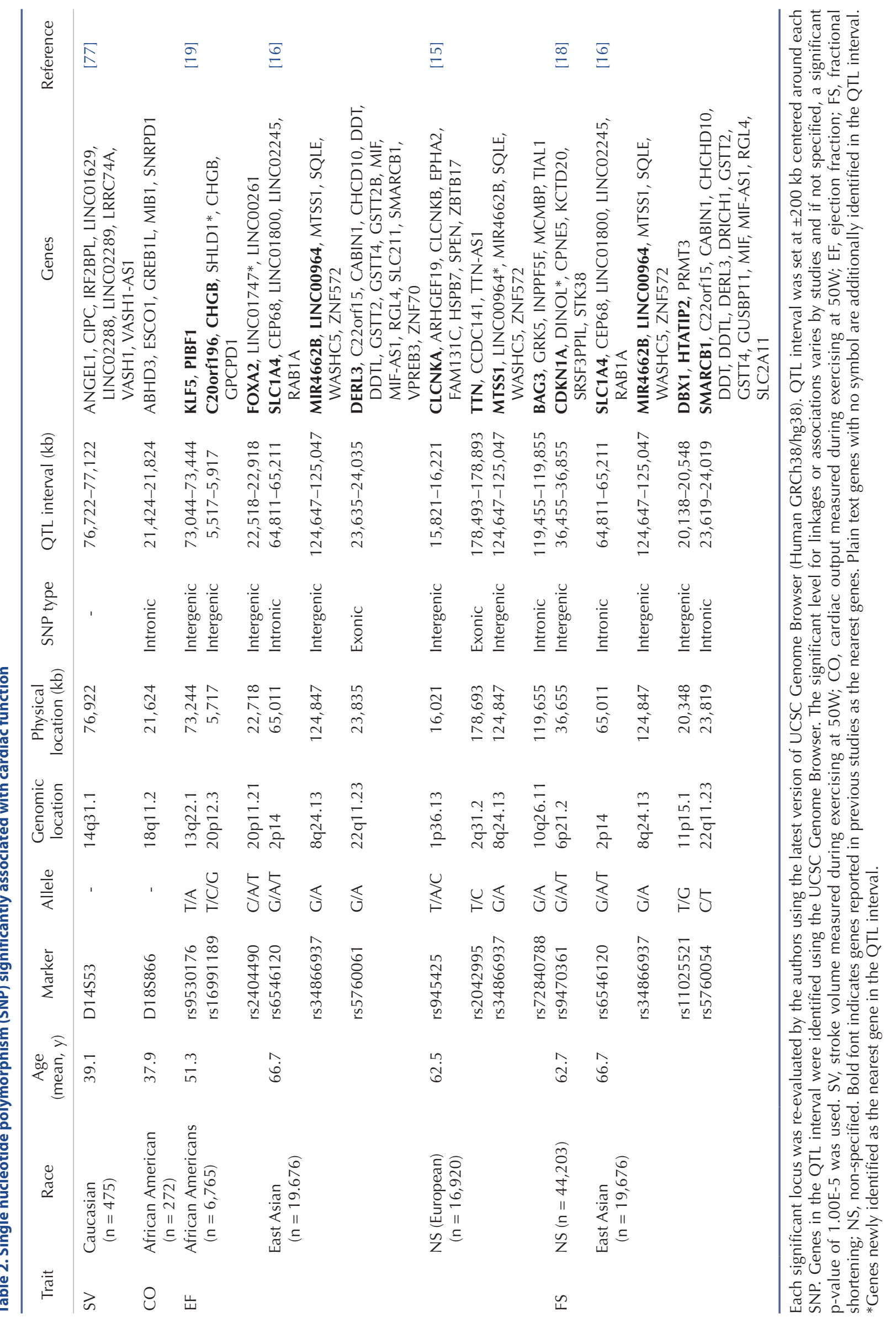


exercise training. We believe that this is the first review of findings from previous genetic studies incorporating the baseline structure and function of the heart as well as its responsiveness to exercise training.

\section{GENETIC REGULATION OF CARDIAC STRUCTURE AND FUNCTION}

Cardiac structural and functional characteristics are important for CVD incidence and are significantly associated with CV morbidity and mortality [50,51,54-56]. Accumulated studies demonstrate that cardiac structural and functional traits are heritable [57], indicating the importance of elucidating the genetic basis of $\mathrm{CV}$ structure and function to understand CVDs. Here, we review results from previous twin and family studies and unbiased large genomic scale association/linkage studies in related and/or unrelated individuals for cardiac structure and function.

\section{Twin studies}

Previous twin studies have revealed the genetic predisposition to cardiac structure and function. In a teenager twin study published in 1991, correlation coefficients for left ventricular mass (LVM) in MZ twins were larger than those of DZ twins [13], indicating the significant role of inheritance in cardiac structural phenotypes. From several twin studies, the $h^{2}$ estimate, which is the proportion of phenotypic variation explained by a shared genome, has been reported for cardiac structural phenotypes. Swan et al. reported a $h^{2}$ of 0.69 for LVM in twins aged 30-85 years from the Western Europe population. Even after adjusting for age, sex, BP, and body weight, the $h^{2}$ estimate remained high (0.53) [13]. Busjahn et al. [58] also found $h^{2}$ estimates of SV, LV endsystolic (LVES), LV end-diastolic (LVED), and average LV mass of $0.77,0.82,0.83$, and 0.84 , respectively, in $13 \mathrm{MZ}$ and $12 \mathrm{DZ}$ twins with a higher $h^{2}$ in MZ than DZ twins for all measurements. In a larger study, the Georgia Cardiovascular Twin Study, which included more than 500 pairs of twins with approximately equal numbers of African Americans and European Americans aged between 14 and 18 years, body mass index-adjusted $h^{2}$ estimates for LV traits, such as WT, LVM, and LV inner diameter (LVID), ranged from 0.21 to 0.71 [59]. In this study, the $h^{2}$ of cardiac structure was substantial in both races. Few Asian twin studies exist to date. Noh et al. [60] investigated the genetic influences on cardiac structure and function in healthy Korean adults comprising 298 MZ twin pairs, $62 \mathrm{DZ}$ twin pairs, 567 siblings, and 354 parents. They reported $h^{2}$ estimates of 0.44 for LVM, 0.47 for LVID, 0.27 for $\mathrm{EF}$, and 0.44 for left atrial volume index adjusted for other confounding factors. Combined, these results from previous twin studies clearly indicate that the cardiac structure and function are genetically influenced, and the extent of the genetic contribution differs depending on race, sex, and age, suggesting that cardiac structure and function are multifactorial traits.

In contrast, several twin studies have suggested no significant influence of inheritance on cardiac structure and function. Fagard et al. [61] found no significant hereditary effects on LVM, LVID, and fractional shortening (FS) in 12 young MZ and $12 \mathrm{DZ}$ twins. Additionally, Bielen et al. [62] found no significant influence of genetic endowment on LVID or WT in seven-year-old twin pairs, although adjusted LVM showed a significant genetic component. A year later, the same investigators reported that in differently aged groups of twins (18 to 31 years old), genetic contributions to LVID and LVM were not present [53]. However, this study found significant genetic contributions to WT, postulating that the extent to which the genetic predisposition explains variation in cardiac structure and function is trait-specific, or, as is common, the number of participants and sensitivity of measurement techniques may have contributed to such a discrepancy.

\section{Family studies}

Several familial studies have conferred familial resemblance in cardiac structure and function. A previous study from The Framingham Heart Study, which is committed to identifying the basis of CVDs, including the genetic factors in a large cohort recruited from 1948, showed an adjusted $\mathrm{LVM} h^{2}$ of 0.32 in 6,218 subjects [52]. The authors also found significant intra-class correlations between first-degree (parent-child, siblings) and second-degree relatives compared to unrelated individuals, showing correlations of $0.15,0.16,0.06$, and 0.05 between parent and child, siblings, second-degree relatives, and spouses, respectively. Another study from the Framingham Heart Study also found that adjusted LVM with other clinical factors, such as age, sex, and body size, showed familial concordance in 5,758 individuals from 1,093 nuclear families [64]. The most recent update from the Framingham Heart Study estimates a $h^{2}$ of 0.4 for LVM [50]. Additionally, 0.3 of the adjusted $h^{2}$ estimate was reported in 149 nuclear families [65]. A parent-offspring study conducted by Palatini et al. [65] claimed a LVM correlation between parent-child of 0.28 , and the authors put forward that although the heredity effect on LVM seems small, the genetic contribution may differ by individual. In other words, the genetic contribution in some subjects may be large, while others may be small, indicating the inter-individual variation. A previous study from the HERITAGE Family Study also reported an adjusted $h^{2}$ of cardiac function measurements, such as SV and Q obtained during 50W exercise of 0.41 and 0.42 , respectively, in 99 Caucasian families [49]. In another research network study, the Genetic Epidemiology Network of Arteriopathy (GENOA) study, which investigated a population consisting primarily of old and unhealthy individuals (mean age; 72.9 years, 13\%; current smokers, 37\%; diabetes or impaired fasting glucose, 70\%; taking anti-hypertensive medications), African Americans presented a $h^{2}$ of 0.34 for LVM, $30 \%$ for interventricular septal WT (IVWT), 0.39 for LV diastolic diameter (LVDD), and 0.42 for 
EF [54]. In 1,305 American Indians aged 45 to 74 involved in the Strong Heart Study, the $h^{2}$ of LVM, LVID, and WT was 0.17, 0.33, and 0.17, respectively [67]. Additionally, the Monitoring Trends and Determinants in Cardiovascular Disease (MONICA) Project by the WHO revealed a significant familial aggregation of LV hypertrophy [68]. There are also ethnical differences in cardiac structures according to the Hypertension Genetic Epidemiology Network (HyperGEN) Study, which includes hypertensive siblings who were diagnosed before reaching 60 years old. Correlations for LVM between siblings were lower in Caucasians (0.22) than African Americans (0.30), while Caucasians had stronger sibling correlations (0.19 vs. 0.11) for WT [69]. In Asian cohorts, the $\operatorname{LVM~} h^{2}$ was reported as 0.26 in 1,145 Chinese Taiwanese subjects, and the authors presented distribution patterns of LVM, highlighting inter-individual variation [70]. The genetic contributions to cardiac structure and function were further supported by the findings of significant parent-child (0.32) and siblingsibling (0.29) correlations, but not in spouse pairs for WT in 181 nuclear family members with African ancestry [51]. A similar approach was used for Caribbean Hispanics (Dominicans) from the Northern Manhattan Family (NOMAS) Study [71]. This study presented an adjusted $h^{2}$ of LVM, WT, LVDD, LVSD, and Posterior WT to $0.49,0.23,0.23,0.33$, and 0.35 , respectively. Combined, these data from previous family studies demonstrate the genetic predisposition to cardiac traits, although $h^{2}$ varies depending on trait and/or study population.

\section{Linkage/association studies}

Linkage and association approaches in related or unrelated individuals allow investigators to identify common genetic variants associated with traits [72]. There have been several linkage and association studies for cardiac structural and functional traits in family members or unrelated individuals. Their findings are summarized in Tables 1 and 2. Arnett et al. [72] first conducted GWAS for LVM in the HyperGen study population consisting of both Caucasians ( $\mathrm{n}=906)$ and African Americans $(\mathrm{n}=1,467)$ and identified novel SNPs for LVM on chromosome 5, 12, and 13 in Caucasians and 5 in African Americans. Among SNPs, rs756529 is located in an intron of KCNB1, which was previously identified by the same research group as a novel candidate gene for LV mass [73]. Two linkage studies for LVM were published from the NOMAS Study. The first used 405 microsatellite quantitative trait loci markers to map variants associated with LVM measured in 1,360 subjects [74]. The authors identified a statistically significant marker (12S1042) associated with LVM on 12p11.23 (11th region, 2nd band and 3rd sub-band on the short arm [p] divided by centromere of chromosome 12). A decade later, the same research group conducted a deeper analysis for this region using denser SNPs $(n=5,477)$, which was then replicated in an additional 618 unrelated Dominicans from the NOMAS and 12 Dominican families. Nine SNPs were reached at the significance prob- ability (rs1046116, rs1035607, rs11168459, rs2191162, rs731236, rs74081827, rs35989439, rs11168985, rs7311790) [20]. They highlighted rs1046116 located in the exonic region of the PKP2 gene, which was implicated in ventricular cardiomyopathy. In 2009, a meta-analysis of GWAS was conducted in seven populationbased cohort studies, including the Cardiovascular Health Study (European ancestry), Rotterdam Study (Rotterdam-population), Multinational Monitoring of Trends and Determinants in Cardiovascular Disease Study (Ausburg-population), Framingham Heart Study (non-specified), Gutenberg Heart Study (Mainz and Mainz-Bingen), Study of Health in Pomerania (West Pomerania), and Austrian Stroke Prevention Study (Graz), and the last two were used for replication [21]. Three loci for LVM on chromosome 2,14 , and 15, two loci for LVDD on chromosome 6, and three loci for WT on chromosome 5, 10, and 16 were identified. However, these loci only explained a small proportion (1\%-3\%) of individual variances in these structural phenotypes. An additional multistage GWAS for cardiac structural traits was conducted in hypertensive subjects from the HyperGEN and GENOA studies [14]. The authors first conducted GWAS in African Americans, and then findings were replicated in Caucasians. Two loci for LVM on chromosome 6 and 16, one locus for LVWT on chromosome 11, and two loci for IVWT on chromosome 2 and 8 were discovered. One SNP, rs1436109, located in intron 1 of NCAM1, was successfully replicated, implying an important role of the NCAM1 gene in cardiac structure. From the Old Order Amish Founder population ( $\mathrm{n}=851)$, who immigrated to the USA, particularly Philadelphia, GWAS for LVM discovered 12 SNPS $\left(\mathrm{p}<10^{-5}\right)$ [75]. None of these significant SNPs were replicated, while one suggestive SNP, rs2207418 (not listed in Table 1), which is located in the intergenic area, was replicated in independent unrelated Caucasians. Using cardiac structure traits obtained from four population-based cohorts of African Americans as a part of the CARe consortium, Fox et al. [19] identified one SNP for LVM on chromosome 8, two SNPs for LVDD on chromosome 7 and 17, and one SNP for IVWT on chromosome 10, although all four SNPs were not replicated in other cohorts. The authors point out that the failure of replication supports race-specific variants associated with cardiac structural traits, indicating the need for additional studies. Recently, the largest genetic association study to date was performed for cardiac phenotypes collected from 46,533 subjects (primarily European ancestry) from the EchoGen consortium comprising 30 studies, including most studies mentioned above [18]. The authors first discovered SNPs via meta-analyses for data from 21 cohort populations ( $\mathrm{n}=30,201)$, and findings were replicated in five independent population-based cohorts $(n=14,002)$ and combined. As a result, one variant for LVM and three variants for LVDD were discovered with regards to the baseline cardiac structure and function. Another study by Aung et al. [15] using data collected from 16,923 subjects of the European UK Biobank also identified one locus for LVM on chromosome 2, three loci for LVED volume (LVEDV) on chromosome 2, 10, and 12, and 
three loci for LVES volume (LVESV) on chromosome 2, 8, and 10. Among them, two loci for LVESV and three loci for LVESV were further replicated, at least at the suggestive level, in an independent cohort from the Multi-Ethnic Study of Atherosclerosis [76]. There is a current GWAS incorporating Asian subjects [16]. In this study, three significant SNPs (rs34866937, rs3812625, and rs11874741) were identified for LVDD on chromosome 8, 10, and 11 , respectively.

Several association studies have been conducted for functional phenotypes of the heart, such as SV, CO, EF, and FS $[15,16,18,19,77]$, and the findings from these studies are summarized in Table 2. A research group previously found that baseline SV and Q obtained during exercise at 50W on a cycle ergometer are variable among individuals $(\mathrm{n}=742)$ in the HERITAGE Family Study [77]. The authors conducted linkage analyses for the variation in baseline SV and Q using 509 genomic markers and found two significantly linked markers, D14S53 and D18S866, for SV in Caucasians and Q in African Americans, respectively. In an aforementioned study by Fox et al. [19], one marker, rs9530176, in chromosome 13 was reported as a significant SNP associated with $\mathrm{EF}$ in individuals from four population-based cohorts of African Americans. A large-scale study originating from the EchoGen consortium also discovered one locus (rs9470361), located in chromosome 6, to be significantly associated with FS [18]. Recently, using a dense marker ( $\mathrm{n}>6,108,953)$, four and three loci significantly associated with FS and EF, respectively, in an Asian population (162,255 Japanese participants) were reported [16]. Another study conducted by Aung et al. [15] found four SNPs for EF located in chromosome 1,2, 8, and 10.

Together, the summarized data from previous twin, family, and linkage or association studies highlight evidence supporting the significant role of genetic components in cardiac phenotypes and offer insights into the genetic architecture of cardiac remodeling. However, none of the SNPs identified by previous linkage or association approaches overlap with each other, and most of the reported genetic variants have not yet had their effects confirmed per se by independent research experiments (i.e., candidate gene study, gene-editing study, etc.), meaning that the additional larger scale experimental studies are needed to provide unquestionable evidence for clinical applications. Ultimately, such data may reveal therapeutic targets for cardiac remodeling and dysfunction which are major causes of deaths in modern human life.

\section{GENETIC REGULATION OF CARDIAC RESPONSES TO EXERCISE TRAINING}

It is evident that exercise training induces positive changes in cardiac structure and function, such as physiological hypertrophy, wall thickening, and improved EF [56,78], thus, it has been used as a non-pharmacological means to prevent CVD and/ or improve CV health, not only for patients but also for healthy individuals. However, recent studies indicate that responses to exercise training are variable across subjects, emphasizing the genetic contribution to training responses $[45,46]$. Therefore, elucidating the genetic basis for responses to exercise training is important in order to constitute the optimally individualized exercise training prescription. Previous studies have reported the significant roles of genetic factors on cardiac responses to exercise training [33,79]; however, the majority of the findings were from studies investigating genotypic effects of one or few candidate genes which were proposed by prior studies (reviewed in [80]), suggesting that the results were dependent on already known information and thus biased. In the sense of that most human traits are polygenic, including responses to exercise [81], unbiased population-based large genome scale studies can provide more information which enables to understand genetic architecture of physiological responses to exercise training comprehensively. Nevertheless, population-based genetic studies exploring cardiac responses to exercise do not dominate literature as much as those for intrinsic or baseline cardiac features, demonstrating the infancy of the study field and necessity for future large population studies identifying genetic determinants responsible for cardiac adaptations to exercise. Although very limited, we here review the previous twin, family, and linkage/association studies addressing this topic.

\section{Twin studies}

Almost four decades ago, investigators examined cardiac responses to exercise in 65 pairs of twins [82]. The authors found that changes in cardiac frequency during submaximal exercise were genetically determined. Several years later (still three decades ago), a different research group assessed the changes in cardiac structural and functional indices during acute bicycle ergometer exercise in 33 healthy male pairs of twins aged from 18 to 31 years. They found different responses to exercise among subjects, indicating the inter-individual variation, and responses were more similar within rather than between twin pairs, supported by estimated $h^{2}$ of 0.24 and 47 for $\mathrm{LV}$ internal dimension and FS, respectively [63]. While in another twin study conducted by Adams et al. [48], changes in LVEDD after 14 weeks of exercise training in MZ twins were not different compared to agematched DZ twins and siblings. Training-induced changes in LVEDD significantly differed from those of non-related individuals [48]. Although a handful of evidence exists, data from these previous twin studies demonstrate that morphological and functional cardiac responses to exercise training are affected, at least in part, by genetic factors. Meanwhile, a relatively recent study published in 2009 aimed to explore the effect of long-term exercise per se on LV mass excluding the genetic influence in twin pairs who were discordant for exercise level for 32 years [83]. In this study, long-term exercise increased LVM normalized to BW when genetic liability was controlled, meaning that cardiac 


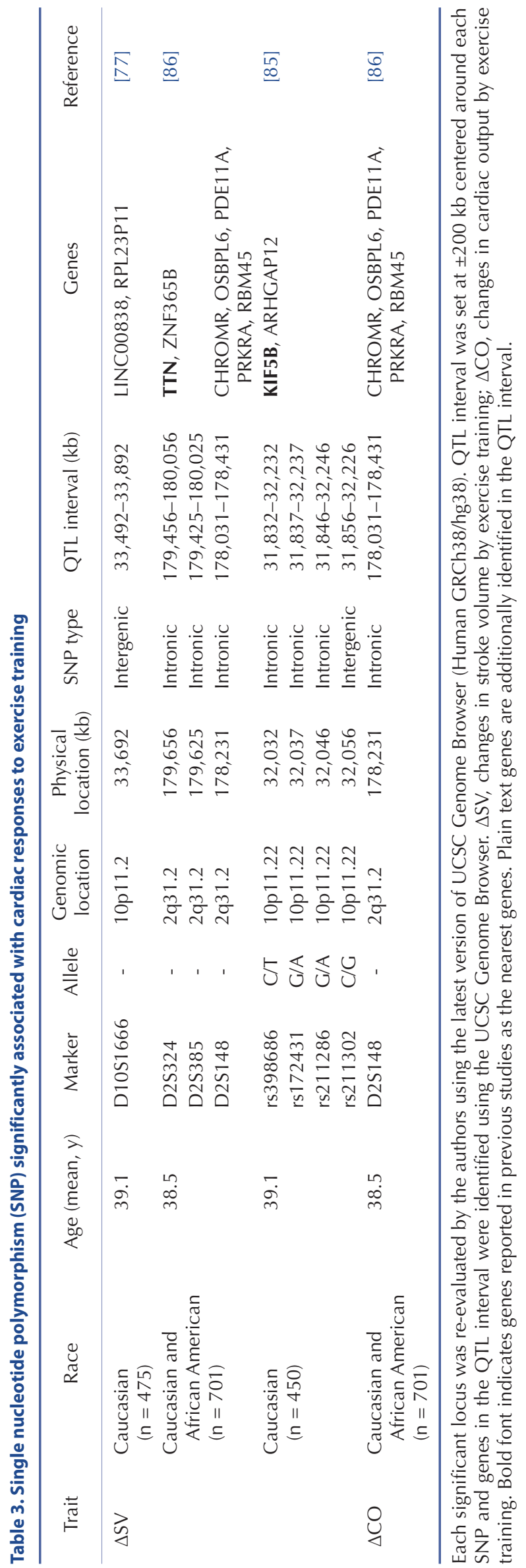

responses to exercise training are multifactorial, interactively affected by both environmental and genetic factors.

\section{Family studies}

To our knowledge, there have been two family studies investigating the genetic influence on cardiac responses to exercise, and these are from the HERITAGE Family Study [47]. The first was published in 2000 [66], in which SV and CO were assessed in 99 Caucasian families who completed a 20 -week standardized aerobic exercise program. The authors reported $h^{2}$ estimates of 0.41 and 0.42 for pre-training SV and Q measured in steady state during exercise at 50 watts on a cycle ergometer, respectively, and 0.29 and 0.38 for the respective changes after endurance exercise training. The $h^{2}$ estimates for the pre-training cardiac function were higher than that of responses to exercise training. The second study investigated the SV and Q changes in response to 20-week exercise training on cycle ergometers in 631 healthy individuals, including both Caucasians $(\mathrm{n}=414)$ and African Americans $(\mathrm{n}=$ 217) aged between 17 and 65 years who had completed the HERITAGE Family Study protocol [84]. This study demonstrated racedependent changes in SV and Q after exercise training. These indicate that cardiac responses to exercise training are genetically affected and provide justification to identify genetic determinants responsible for the genetic influence on cardiac function.

\section{Linkage/association studies}

Rankinen et al. [77], for the first time, conducted a genomewide linkage scan for changes in SV and Q after standardized 20-week exercise training in 701 individuals consisting of 483 Caucasians and 259 African Americans from the HERITAGE Family Study. A total of 509 genomic markers was used to scan the genome in this study. For Caucasians, one marker, D10S1666, located on 10p11.2 (11th region and 2nd band on the short arm [p] divided by centromere of chromosome 10), was significantly ( $\mathrm{p}<$ 0.0023) associated with changes in SV after exercise training, and several other markers were identified as suggestive SNPs associated with SV and CO responses to exercise training. In contrast, for African Americans, none of the markers were significantly associated with cardiac response traits to training, although several suggestive linkages $(0.01>p>0.0023)$ were also identified (Table 3). Several potential candidate genes were identified near the significant and/or suggestive SNPs. Two follow-up studies were performed to scrutinize the results of the prior study $[85,86]$. One closely examined genomic region was 2q31 (31th region on the long arm [q] divided by centromere of chromosome 2), where a suggestive linkage was found for SV response to exercise training [86]. Using an additional 12 microsatellite markers, the linkage signal for this region was amplified with an average density of one marker per $2.3 \mathrm{Mb}$. The authors found the two strongest markers located in and near the Titin gene, which is known to be 
a biological key player of the Frank-Starling mechanism in the heart; however, since this linkage was observed only in Caucasian, not in African American subjects, much more detailed DNA variants in this gene need to be sequenced further; however, no additional follow-up study has been conducted so far. Another focused on the genomic region 10p11 (11th region on the short arm [p] divided by centromere of chromosome 10), which was significantly associated with changes in SV after exercise training [85]. Through the deeper mapping using six microsatellite markers, they narrowed down the linkage region into a $7 \mathrm{Mb}$ area, and an additional association analysis for this region was performed using 90 SNPs. Consequently, the authors found the KIF5B gene loci suggestively associated with SV responses to exercise training, which is known to have a biological role in mitochondrial localization and biogenesis. Particularly, the authors highlighted sequence variants in promoter region of KIF5B, implying that transcriptional regulation by enhancers, repressors or epigenetic regulators would be one of underlying mechanisms for interindividual differences in cardiac responses to exercise training.

Despite these previous data demonstrating the salient role of genetic components on cardiac response to exercise training, a handful of findings from previous studies have not been replicated and potential candidate genes have not been considered in any other independent studies. Moreover, any linkage/association studies for cardiac structural responses to exercise training have not yet been conducted, referring to the myriad research agenda left for this study field. Given the notion that responses to exercise training are polygenic and multifactorial and dramatic advancements in genome sequencing techniques, larger-scale future studies based on a large population are warranted to unveil the genetic basis of cardiac responses to exercise.

\section{CONCLUSION}

Here, we review previous findings highlighting the genetic contribution to cardiac phenotypes and responsiveness to exercise training. Accumulated results have shown that baseline cardiac structure and function are heritable and complex traits. Researchers have explored twin, family, and linkage/association studies to elucidate the genetic basis and many loci associated with LVM, LVDD, WT, LVEDV, and LVESV (Table 1), and SV, CO, EF, and FS (Table 2) have been reported. Meanwhile, it has been well-characterized that exercise training can improve cardiac health and prevent CVD; however, inter-individual variation in responses to exercise is currently highlighted, demonstrating that responses to exercise training are also genetically determined. A handful of evidence from the HERITAGE Family Study has provided several genetic variants modestly associated with cardiac responses to exercise training (Table 3). Nevertheless, the vast majority of mapped loci associated with the baseline structure and function of the heart as well as their responsiveness to exercise training are not in conjunction with one another across studies. This may be due to the heterogeneity in race, age, gender, environments and effect sizes. Therefore, collaboration and collation of larger cohorts with much denser genome sequencing are required to overcome these limitaions. Additionally, translating genomic localization into the biological mechanisms remains a mystery. Considered with swift advances in genome editing techniques, future studies are warranted to further evaluate the biological functions of reported genetic variants and loci, which will serve as the basis for potential therapeutic targets and personalized risk stratification strategy for cardiac diseases in future.

\section{ACKNOWLEDGEMENTS}

This study was supported by the Research Program funded by SeoulTech (Seoul National University of Science and Technology) (SKK).

\section{CONFLICTS OF INTEREST}

The authors declare no conflicts of interest.

\section{REFERENCES}

1. Joseph P, Leong D, McKee M, Anand SS, Schwalm JD, Teo K, Mente A, Yusuf S. Reducing the global burden of cardiovascular disease, part 1: the epidemiology and risk factors. Circ Res. 2017;121:677694.

2. Heidenreich PA, Trogdon JG, Khavjou OA, Butler J, Dracup K, Ezekowitz MD, Finkelstein EA, Hong Y, Johnston SC, Khera A, LloydJones DM, Nelson SA, Nichol G, Orenstein D, Wilson PW, Woo YJ. Forecasting the future of cardiovascular disease in the United States: a policy statement from the American Heart Association. Circulation. 2011;123:933-944.

3. Wu A. Heart failure. Ann Intern Med. 2018;168:ITC81-ITC96.

4. Liu S, Li Y, Zeng X, Wang H, Yin P, Wang L, Liu Y, Liu J, Qi J, Ran S, Yang S, Zhou M. Burden of cardiovascular diseases in China, 19902016: findings from the 2016 Global Burden of Disease study. JAMA Cardiol. 2019;4:342-352.

5. Gu D, Gupta A, Muntner P, Hu S, Duan X, Chen J, Reynolds RF, Whelton PK, He J. Prevalence of cardiovascular disease risk factor clustering among the adult population of China: results from the International Collaborative Study of Cardiovascular Disease in Asia (InterAsia). Circulation. 2005;112:658-665.

6. Lloyd-Jones DM, Nam BH, D'Agostino RB Sr, Levy D, Murabito JM, Wang TJ, Wilson PW, O'Donnell CJ. Parental cardiovascular disease as a risk factor for cardiovascular disease in middle-aged adults: a prospective study of parents and offspring. JAMA. 2004;291:22042211.

7. Warren HR, Evangelou E, Cabrera CP, Gao H, Ren M, Mifsud B, Ntalla I, Surendran P, Liu C, Cook JP, Kraja AT, Drenos F, Loh M, 
Verweij N, Marten J, Karaman I, Lepe MP, O'Reilly PF, Knight J, Snieder $\mathrm{H}$, et al. Genome-wide association analysis identifies novel blood pressure loci and offers biological insights into cardiovascular risk. Nat Genet. 2017;49:403-415.

8. Nelson CP, Goel A, Butterworth AS, Kanoni S, Webb TR, Marouli E, Zeng L, Ntalla I, Lai FY, Hopewell JC, Giannakopoulou O, Jiang T, Hamby SE, Di Angelantonio E, Assimes TL, Bottinger EP, Chambers JC, Clarke R, Palmer CNA, Cubbon RM, et al. Association analyses based on false discovery rate implicate new loci for coronary artery disease. Nat Genet. 2017;49:1385-1391.

9. Sivapalaratnam S, Motazacker MM, Maiwald S, Hovingh GK, Kastelein JJ, Levi M, Trip MD, Dallinga-Thie GM. Genome-wide association studies in atherosclerosis. Curr Atheroscler Rep. 2011; 13:225-232.

10. Smith NL, Felix JF, Morrison AC, Demissie S, Glazer NL, Loehr LR, Cupples LA, Dehghan A, Lumley T, Rosamond WD, Lieb W, Rivadeneira F, Bis JC, Folsom AR, Benjamin E, Aulchenko YS, Haritunians T, Couper D, Murabito J, Wang YA, et al. Association of genome-wide variation with the risk of incident heart failure in adults of European and African ancestry: a prospective meta-analysis from the cohorts for heart and aging research in genomic epidemiology (CHARGE) consortium. Circ Cardiovasc Genet. 2010;3:256-266.

11. Burchfield JS, Xie M, Hill JA. Pathological ventricular remodeling: mechanisms: part 1 of 2. Circulation. 2013;128:388-400.

12. Tsao CW, Gona PN, Salton CJ, Chuang ML, Levy D, Manning WJ, O'Donnell CJ. Left ventricular structure and risk of cardiovascular events: a Framingham Heart Study cardiac magnetic resonance study. J Am Heart Assoc. 2015;4:e002188.

13. Swan L, Birnie DH, Padmanabhan S, Inglis G, Connell JM, Hillis WS. The genetic determination of left ventricular mass in healthy adults. Eur Heart J. 2003;24:577-582.

14. Arnett DK, Meyers KJ, Devereux RB, Tiwari HK, Gu CC, Vaughan LK, Perry RT, Patki A, Claas SA, Sun YV, Broeckel U, Kardia SL. Genetic variation in NCAM1 contributes to left ventricular wall thickness in hypertensive families. Circ Res. 2011;108:279-283.

15. Aung N, Vargas JD, Yang C, Cabrera CP, Warren HR, Fung K, Tzanis E, Barnes MR, Rotter JI, Taylor KD, Manichaikul AW, Lima JAC, Bluemke DA, Piechnik SK, Neubauer S, Munroe PB, Petersen SE. Genome-wide analysis of left ventricular image-derived phenotypes identifies fourteen loci associated with cardiac morphogenesis and heart failure development. Circulation. 2019;140:1318-1330.

16. Kanai M, Akiyama M, Takahashi A, Matoba N, Momozawa Y, Ikeda M, Iwata N, Ikegawa S, Hirata M, Matsuda K, Kubo M, Okada Y, Kamatani Y. Genetic analysis of quantitative traits in the Japanese population links cell types to complex human diseases. Nat Genet. 2018;50:390-400.

17. Do AN, Zhao W, Baldridge AS, Raffield LM, Wiggins KL, Shah SJ, Aslibekyan S, Tiwari HK, Limdi N, Zhi D, Sitlani CM, Taylor KD, Psaty BM, Sotoodehnia N, Brody JA, Rasmussen-Torvik LJ, LloydJones D, Lange LA, Wilson JG, Smith JA, et al. Genome-wide metaanalysis of SNP and antihypertensive medication interactions on left ventricular traits in African Americans. Mol Genet Genomic Med. 2019;7:e00788.

18. Wild PS, Felix JF, Schillert A, Teumer A, Chen MH, Leening MJG, Völker U, Großmann V, Brody JA, Irvin MR, Shah SJ, Pramana S, Lieb W, Schmidt R, Stanton AV, Malzahn D, Smith AV, Sundström J, Minelli C, Ruggiero D, et al. Large-scale genome-wide analysis identifies genetic variants associated with cardiac structure and function. J Clin Invest. 2017;127:1798-1812.

19. Fox ER, Musani SK, Barbalic M, Lin H, Yu B, Ogunyankin KO, Smith NL, Kutlar A, Glazer NL, Post WS, Paltoo DN, Dries DL, Farlow DN, Duarte CW, Kardia SL, Meyers KJ, Sun YV, Arnett DK, Patki AA, Sha J, et al. Genome-wide association study of cardiac structure and systolic function in African Americans: the Candidate Gene Association Resource (CARe) study. Circ Cardiovasc Genet. 2013;6:37-46.

20. Dueker ND, Guo S, Beecham A, Wang L, Blanton SH, Di Tullio MR, Rundek T, Sacco RL. Sequencing of linkage region on chromosome 12p11 identifies PKP2 as a candidate gene for left ventricular mass in Dominican families. G3 (Bethesda). 2018;8:659-668.

21. Vasan RS, Glazer NL, Felix JF, Lieb W, Wild PS, Felix SB, Watzinger N, Larson MG, Smith NL, Dehghan A, Grosshennig A, Schillert A, Teumer A, Schmidt R, Kathiresan S, Lumley T, Aulchenko YS, König IR, Zeller T, Homuth G, et al. Genetic variants associated with cardiac structure and function: a meta-analysis and replication of genome-wide association data. JAMA. 2009;302:168-178.

22. Kathiresan S, Srivastava D. Genetics of human cardiovascular disease. Cell. 2012;148:1242-1257.

23. Kim MS, Patel KP, Teng AK, Berens AJ, Lachance J. Genetic disease risks can be misestimated across global populations. Genome Biol. 2018;19:179.

24. Zadro JR, Shirley D, Andrade TB, Scurrah KJ, Bauman A, Ferreira $\mathrm{PH}$. The beneficial effects of physical activity: is it down to your genes? A systematic review and meta-analysis of twin and family studies. Sports Med Open. 2017;3:4.

25. Galton F. The history of twins, as a criterion of the relative powers of nature and nurture (1,2). Int J Epidemiol. 2012;41:905-911.

26. Boomsma D, Busjahn A, Peltonen L. Classical twin studies and beyond. Nat Rev Genet. 2002;3:872-882.

27. Badzioch MD, Igo RP Jr, Gagnon F, Brunzell JD, Krauss RM, Motulsky AG, Wijsman EM, Jarvik GP. Low-density lipoprotein particle size loci in familial combined hyperlipidemia: evidence for multiple loci from a genome scan. Arterioscler Thromb Vasc Biol. 2004;24:1942-1950.

28. Borecki IB, Province MA. Genetic and genomic discovery using family studies. Circulation. 2008;118:1057-1063.

29. Zhao LP, Hsu L, Davidov O, Potter J, Elston RC, Prentice RL. Population-based family study designs: an interdisciplinary research framework for genetic epidemiology. Genet Epidemiol. 1997;14:365388.

30. Wang Y, Wang JG. Genome-wide association studies of hypertension and several other cardiovascular diseases. Pulse (Basel). 2019;6:169-186.

31. Stranger BE, Stahl EA, Raj T. Progress and promise of genomewide association studies for human complex trait genetics. Genetics. 2011;187:367-383.

32. Kessler T, Vilne B, Schunkert H. The impact of genome-wide association studies on the pathophysiology and therapy of cardiovascular disease. EMBO Mol Med. 2016;8:688-701.

33. Fiuza-Luces C, Santos-Lozano A, Joyner M, Carrera-Bastos P, Picazo O, Zugaza JL, Izquierdo M, Ruilope LM, Lucia A. Exercise benefits in cardiovascular disease: beyond attenuation of traditional risk factors. Nat Rev Cardiol. 2018;15:731-743.

34. Church TS, Earnest CP, Skinner JS, Blair SN. Effects of differ- 
ent doses of physical activity on cardiorespiratory fitness among sedentary, overweight or obese postmenopausal women with elevated blood pressure: a randomized controlled trial. JAMA. 2007; 297:2081-2091.

35. Jeong SW, Kim SH, Kang SH, Kim HJ, Yoon CH, Youn TJ, Chae IH. Mortality reduction with physical activity in patients with and without cardiovascular disease. Eur Heart J. 2019;40:3547-3555.

36. Nystoriak MA, Bhatnagar A. Cardiovascular effects and benefits of exercise. Front Cardiovasc Med. 2018;5:135.

37. Lavie CJ, Arena R, Swift DL, Johannsen NM, Sui X, Lee DC, Earnest CP, Church TS, O'Keefe JH, Milani RV, Blair SN. Exercise and the cardiovascular system: clinical science and cardiovascular outcomes. Circ Res. 2015;117:207-219.

38. Arbab-Zadeh A, Perhonen M, Howden E, Peshock RM, Zhang R, Adams-Huet B, Haykowsky MJ, Levine BD. Cardiac remodeling in response to 1 year of intensive endurance training. Circulation. 2014;130:2152-2161.

39. Kim SK, Massett MP. Genetic regulation of endothelial vasomotor function. Front Physiol. 2016;7:571.

40. Álvarez C, Ramírez-Campillo R, Ramírez-Vélez R, Izquierdo M. Effects and prevalence of nonresponders after 12 weeks of high-intensity interval or resistance training in women with insulin resistance: a randomized trial. J Appl Physiol. 2017;122:985-996.

41. Bonafiglia JT, Rotundo MP, Whittall JP, Scribbans TD, Graham RB, Gurd BJ. Inter-individual variability in the adaptive responses to endurance and sprint interval training: a randomized crossover study. PLoS One. 2016;11:e0167790.

42. Bouchard C, Rankinen T. Individual differences in response to regular physical activity. Med Sci Sports Exerc. 2001;33(6 Suppl):S446S451; discussion S452-S453.

43. Williams CJ, Williams MG, Eynon N, Ashton KJ, Little JP, Wisloff $\mathrm{U}$, Coombes JS. Genes to predict VO2max trainability: a systematic review. BMC Genomics. 2017;18(Suppl 8):831.

44. Bouchard C, Blair SN, Church TS, Earnest CP, Hagberg JM, Häkkinen K, Jenkins NT, Karavirta L, Kraus WE, Leon AS, Rao DC, Sarzynski MA, Skinner JS, Slentz CA, Rankinen T. Adverse metabolic response to regular exercise: is it a rare or common occurrence? PLoS One. 2012;7:e37887.

45. Bouchard C, Rankinen T, Timmons JA. Genomics and genetics in the biology of adaptation to exercise. Compr Physiol. 2011;1:16031648.

46. Ross R, Goodpaster BH, Koch LG, Sarzynski MA, Kohrt WM, Johannsen NM, Skinner JS, Castro A, Irving BA, Noland RC, Sparks LM, Spielmann G, Day AG, Pitsch W, Hopkins WG, Bouchard C. Precision exercise medicine: understanding exercise response variability. Br J Sports Med. 2019;53:1141-1153.

47. Bouchard C, Leon AS, Rao DC, Skinner JS, Wilmore JH, Gagnon J. The HERITAGE family study. Aims, design, and measurement protocol. Med Sci Sports Exerc. 1995;27:721-729.

48. Adams TD, Yanowitz FG, Fisher AG, Ridges JD, Nelson AG, Hagan AD, Williams RR, Hunt SC. Heritability of cardiac size: an echocardiographic and electrocardiographic study of monozygotic and dizygotic twins. Circulation. 1985;71:39-44.

49. Fox ER, Klos KL, Penman AD, Blair GJ, Blossom BD, Arnett D, Devereux RB, Samdarshi T, Boerwinkle E, Mosley TH Jr. Heritability and genetic linkage of left ventricular mass, systolic and diastolic function in hypertensive African Americans (from the GENOA
Study). Am J Hypertens. 2010;23:870-875.

50. Garner C, Lecomte E, Visvikis S, Abergel E, Lathrop M, Soubrier F. Genetic and environmental influences on left ventricular mass. A family study. Hypertension. 2000;36:740-746.

51. Juo SH, Di Tullio MR, Lin HF, Rundek T, Boden-Albala B, Homma S, Sacco RL. Heritability of left ventricular mass and other morphologic variables in Caribbean Hispanic subjects: the Northern Manhattan Family Study. J Am Coll Cardiol. 2005;46:735-737.

52. Lam CS, Liu X, Yang Q, Larson MG, Pencina MJ, Aragam J, Redfield MM, Benjamin EJ, Vasan RS. Familial aggregation of left ventricular geometry and association with parental heart failure: the Framingham Heart Study. Circ Cardiovasc Genet. 2010;3:492-498.

53. Post WS, Larson MG, Myers RH, Galderisi M, Levy D. Heritability of left ventricular mass: the Framingham Heart Study. Hypertension. 1997;30:1025-1028.

54. Bella JN, MacCluer JW, Roman MJ, Almasy L, North KE, Best LG, Lee ET, Fabsitz RR, Howard BV, Devereux RB. Heritability of left ventricular dimensions and mass in American Indians: the Strong Heart Study. J Hypertens. 2004;22:281-286.

55. Bielen E, Fagard R, Amery A. The inheritance of left ventricular structure and function assessed by imaging and Doppler echocardiography. Am Heart J. 1991;121(6 Pt 1):1743-1749.

56. Hannukainen JC, Kujala UM, Toikka J, Heinonen OJ, Kapanen J, Vahlberg T, Kaprio J, Kalliokoski KK. Cardiac structure and function in monozygotic twin pairs discordant for physical fitness. $J$ Appl Physiol. 2005;99:535-541.

57. Verhaaren HA, Schieken RM, Mosteller M, Hewitt JK, Eaves LJ, Nance WE. Bivariate genetic analysis of left ventricular mass and weight in pubertal twins (the Medical College of Virginia twin study). Am J Cardiol. 1991;68:661-668.

58. Busjahn CA, Schulz-Menger J, Abdel-Aty H, Rudolph A, Jordan J, Luft FC, Busjahn A. Heritability of left ventricular and papillary muscle heart size: a twin study with cardiac magnetic resonance imaging. Eur Heart J. 2009;30:1643-1647.

59. Kapuku GK, Ge D, Vemulapalli S, Harshfield GA, Treiber FA, Snieder $\mathrm{H}$. Change of genetic determinants of left ventricular structure in adolescence: longitudinal evidence from the Georgia cardiovascular twin study. Am J Hypertens. 2008;21:799-805.

60. Noh HM, Lee SC, Park SW, Sung J, Song YM. Genetic influence on left ventricular structure and function: a Korean twin and family study. Twin Res Hum Genet. 2015;18:281-289.

61. Fagard R, Van Den Broeke C, Bielen E, Amery A. Maximum oxygen uptake and cardiac size and function in twins. Am J Cardiol. 1987;60:1362-1367.

62. Bielen E, Fagard R, Amery A. Inheritance of heart structure and physical exercise capacity: a study of left ventricular structure and exercise capacity in 7-year-old twins. Eur Heart J. 1990;11:7-16.

63. Bielen EC, Fagard RH, Amery AK. Inheritance of acute cardiac changes during bicycle exercise: an echocardiographic study in twins. Med Sci Sports Exerc. 1991;23:1254-1259.

64. Vasan RS, Larson MG, Aragam J, Wang TJ, Mitchell GF, Kathiresan S, Newton-Cheh C, Vita JA, Keyes MJ, O'Donnell CJ, Levy D, Benjamin EJ. Genome-wide association of echocardiographic dimensions, brachial artery endothelial function and treadmill exercise responses in the Framingham Heart Study. BMC Med Genet. 2007;8(Suppl 1):S2.

65. Palatini P, Krause L, Amerena J, Nesbitt S, Majahalme S, Tikhonoff 
V, Valentini M, Julius S. Genetic contribution to the variance in left ventricular mass: the Tecumseh Offspring Study. J Hypertens. 2001;19:1217-1222.

66. An P, Rice T, Gagnon J, Leon AS, Skinner JS, Bouchard C, Rao DC, Wilmore JH. Familial aggregation of stroke volume and cardiac output during submaximal exercise: the HERITAGE Family Study. Int J Sports Med. 2000;21:566-572.

67. Schunkert H, Bröckel U, Hengstenberg C, Luchner A, Muscholl MW, Kurzidim K, Kuch B, Döring A, Riegger GA, Hense HW. Familial predisposition of left ventricular hypertrophy. J Am Coll Cardiol. 1999;33:1685-1691.

68. Arnett DK, Hong Y, Bella JN, Oberman A, Kitzman DW, Hopkins PN, Rao DC, Devereux RB. Sibling correlation of left ventricular mass and geometry in hypertensive African Americans and whites: the HyperGEN study. Hypertension Genetic Epidemiology Network. Am J Hypertens. 2001;14:1226-1230.

69. Chien KL, Hsu HC, Su TC, Chen MF, Lee YT. Heritability and major gene effects on left ventricular mass in the Chinese population: a family study. BMC Cardiovasc Disord. 2006;6:37.

70. Peterson VR, Norton GR, Redelinghuys M, Libhaber CD, Maseko $\mathrm{MJ}$, Majane $\mathrm{OH}$, Brooksbank R, Woodiwiss AJ. Intrafamilial aggregation and heritability of left ventricular geometric remodeling is independent of cardiac mass in families of African ancestry. Am J Hypertens. 2015;28:657-663.

71. Balding DJ. A tutorial on statistical methods for population association studies. Nat Rev Genet. 2006;7:781-791.

72. Arnett DK, Li N, Tang W, Rao DC, Devereux RB, Claas SA, Kraemer R, Broeckel U. Genome-wide association study identifies single-nucleotide polymorphism in KCNB1 associated with left ventricular mass in humans: the HyperGEN Study. BMC Med Genet. 2009;10:43.

73. Tang W, Arnett DK, Devereux RB, Panagiotou D, Province MA, Miller MB, de Simone G, Gu C, Ferrell RE. Identification of a novel 5-base pair deletion in calcineurin B (PPP3R1) promoter region and its association with left ventricular hypertrophy. Am Heart J. 2005;150:845-851.

74. Wang L, Beecham A, Di Tullio MR, Slifer S, Blanton SH, Rundek T, Sacco RL. Novel quantitative trait locus is mapped to chromosome 12p11 for left ventricular mass in Dominican families: the Family Study of Stroke Risk and Carotid Atherosclerosis. BMC Med Genet. 2009;10:74.

75. Parsa A, Chang YP, Kelly RJ, Corretti MC, Ryan KA, Robinson SW, Gottlieb SS, Kardia SL, Shuldiner AR, Liggett SB. Hypertrophyassociated polymorphisms ascertained in a founder cohort applied to heart failure risk and mortality. Clin Transl Sci. 2011;4:17-23.

76. Bild DE, Bluemke DA, Burke GL, Detrano R, Diez Roux AV, Folsom AR, Greenland P, Jacob DR Jr, Kronmal R, Liu K, Nelson JC, O'Leary D, Saad MF, Shea S, Szklo M, Tracy RP. Multi-Ethnic Study of Atherosclerosis: objectives and design. Am J Epidemiol. 2002;156:871-881.

77. Rankinen T, An P, Pérusse L, Rice T, Chagnon YC, Gagnon J, Leon AS, Skinner JS, Wilmore JH, Rao DC, Bouchard C. Genome-wide linkage scan for exercise stroke volume and cardiac output in the HERITAGE Family Study. Physiol Genomics. 2002;10:57-62.

78. Vega RB, Konhilas JP, Kelly DP, Leinwand LA. Molecular mechanisms underlying cardiac adaptation to exercise. Cell Metab. 2017;25:1012-1026.

79. Eynon N, Ruiz JR, Oliveira J, Duarte JA, Birk R, Lucia A. Genes and elite athletes: a roadmap for future research. J Physiol (Lond). 2011;589(Pt 13):3063-3070.

80. Bray MS, Hagberg JM, Pérusse L, Rankinen T, Roth SM, Wolfarth $\mathrm{B}$, Bouchard C. The human gene map for performance and healthrelated fitness phenotypes: the 2006-2007 update. Med Sci Sports Exerc. 2009;41:35-73.

81. Bouchard C, Sarzynski MA, Rice TK, Kraus WE, Church TS, Sung YJ, Rao DC, Rankinen T. Genomic predictors of the maximal $\mathrm{O}_{2}$ uptake response to standardized exercise training programs. J Appl Physiol. 2011;110:1160-1170.

82. Kagamimori S, Robson JM, Heywood C, Cotes JE. Genetic and environmental determinants of the cardio-respiratory response to submaximal exercise--a six-year follow-up study of twins. Ann Hum Biol. 1984;11:29-38.

83. Mutikainen S, Perhonen M, Alén M, Leskinen T, Karjalainen J, Rantanen T, Kaprio J, Kujala UM. Effects of long-term physical activity on cardiac structure and function: a twin study. J Sports Sci Med. 2009;8:533-542.

84. Wilmore JH, Stanforth PR, Gagnon J, Rice T, Mandel S, Leon AS, Rao DC, Skinner JS, Bouchard C. Cardiac output and stroke volume changes with endurance training: the HERITAGE Family Study. Med Sci Sports Exerc. 2001;33:99-106.

85. Argyropoulos G, Stütz AM, Ilnytska O, Rice T, Teran-Garcia M, Rao DC, Bouchard C, Rankinen T. KIF5B gene sequence variation and response of cardiac stroke volume to regular exercise. Physiol Genomics. 2009;36:79-88.

86. Rankinen T, Rice T, Boudreau A, Leon AS, Skinner JS, Wilmore JH, Rao DC, Bouchard C. Titin is a candidate gene for stroke volume response to endurance training: the HERITAGE Family Study. Physiol Genomics. 2003;15:27-33. 